\title{
Trapdoor spiders of the genus Cyclocosmia Ausserer, I87I from China and Vietnam (Araneae, Ctenizidae)
}

\author{
Xin $\mathrm{Xu}^{1,2}$, Chen $\mathrm{Xu}^{2}$, Fan $\mathrm{Li}^{2}$, Dinh Sac Pham ${ }^{4}$, Daiqin $\mathrm{Li}^{3}$ \\ I College of Life Sciences, Hunan Normal University, Changsha, Hunan, China 2 Centre for Behavioural Eco- \\ logy and Evolution (CBEE), College of Life Sciences, Hubei University, Wuhan, Hubei, China 3 Department \\ of Biological Sciences, National University of Singapore, 14 Science Drive 4, Singapore 1175434 Graduate \\ University of Science and Technology, Vietnam Academy of Science and Technology, 18 Hoang Quoc Viet, Cau \\ Giay, Hanoi, Vietnam \\ Corresponding authors: Xin Xu (xuxin_09@163.com); Daiqin Li (dbslidq@nus.edu.sg)
}

Academic editor: I. Agnarsson | Received 14 October 2016 | Accepted 12 December 2016 | Published 6 January 2017

http://zoobank.org/ED62B710-DC5C-4036-A4BD-E93752EDD311

Citation: Xu X, Xu C, Li F, Pham DS, Li D (2017) Trapdoor spiders of the genus Cyclocosmia Ausserer, 1871 from China and Vietnam (Araneae, Ctenizidae). ZooKeys 643: 75-85. https://doi.org/10.3897/zookeys.643.10797

\begin{abstract}
A species of the genus Cyclocosmia Ausserer, 1871 collected from Guizhou Province, China is diagnosed and described as new to science: $C$. liui $\mathrm{Xu}, \mathrm{Xu} \& \mathrm{Li}, \mathbf{s p} . \mathbf{n}$. (ㅇ). New records of $C$. latusicosta Zhu, Zhang \& Zhang, 2006 () from China (Yunnan Province) and Vietnam (Vinh Phuc Province, Ninh Binh Province), and C. ricketti (Pocock, 1901) collected from Jiangxi Province, China are also reported in this study.
\end{abstract}

\section{Keywords}

China, Cyclocosmia, taxonomy, trapdoor spider, Vietnam

\section{Introduction}

The mygalomorph family Ctenizidae is ancient, long-lived, regionally endemic and dispersal-limited, and thus is of long-standing and persistent conservation significance in many regions of the world (Zhu et al. 2006; Opatova et al. 2013, 2016). Ctenizids are widely distributed in east and southeast Asia, north and south America, the Mediterranean region, southern Africa and Australia (World Spider Catalog 2016). These medium-sized, ground-dwelling spiders usually construct silk-lined burrows underground,

Copyright $X i n$ Xu et al. This is an open access article distributed under the terms of the Creative Commons Attribution License (CC BY 4.0), which permits unrestricted use, distribution, and reproduction in any medium, provided the original author and source are credited. 
which open to the surface with a trapdoor. Trapdoors covered with a layer of leaf litter and/or a sheet of moss match the background well, thus making them very difficult to spot in the field (Gertsch and Wallace 1936; Gertsch and Platnick 1975; Hunt 1976; Bond and Coyle 1995).

Despite being present across much of the world, Ctenizidae is represented by only approximately 130 extant species-level taxa (World Spider Catalog 2016). These taxa are conventionally divided into nine genera and two subfamilies, Ctenizinae and Ummidiinae (Ortiz 2007). Ummidiinae includes three genera, Conothele Thorell, 1878, Hebestatis Simon, 1903 and Ummidia Thorell, 1875. Hebestatis was recently removed from this subfamily since it posseses lateral sternal sigilla and a less pronounced and glabrous dorsal saddle on the tibia III, but lacks curvy spines, tarsal clavate trichobothria and centrally sclerotized spermathecae (Decae 2010). The taxonomic position of Hebestatis therefore remains unclear (but see Garrison et al. 2016). The subfamily Ctenizinae contains six genera, Bothriocyrtum Simon, 1891, Cteniza Latreille, 1829, Cyrtocarenum Ausserer, 1871, Cyclocosmia Ausserer, 1871, Latouchia Pocock, 1901, and Stasimopus Simon, 1892. However, this grouping currently lacks the support of any identified synpomorphies (Raven 1985).

Despite being a small genus, Cyclocosmia contains some of the most fascinating spiders in the world (Buchli 1969; Gertsch and Platnick 1975). Their abdomens are abruptly truncated and finish in a hard, heavily sclerotized disc that is enhanced by a series of raised ribs separated by narrow grooves (Gertsch and Platnick 1975). This acts as a distinctive morphological defence to cope with intruders, such as predators, into the borrow. When the spider retreats head-first into its burrow, the abdominal disc fits tightly against the round walls of the burrow and forms an impenetrable false trapdoor (Gertsch and Wallance 1936; Gertsch and Platnick 1975). Cyclocosmia spiders usually build their burrows in steeply sloping banks of sandy clay (Fig. 1A). The trapdoor is usually made of silk mixed with soil and covered with a layer of leaf litter and/or moss. Like many other ctenizids, Cyclocosmia spiders are very difficult to find in the field because the remarkably effective camouflage of their trapdoors. Therefore, they are often regarded as one of the rarest spiders (Gertsch and Wallance 1936; Gertsch and Platnick 1975; Zhu et al. 2006).

Cyclocosmia is currently represented by seven nominal species: two in the USA ( $C$. torreya Gertsch \& Platnick, 1975 and C. truncata (Hertz, 1841)), one in Mexico and Guatemala (C. loricata (C. K. Koch, 1842)) and four in East and Southeast Asia (C. latusicosta Zhu, Zhang \& Zhang, 2006 and C. ricketti (Pocock, 1901) in China, C. lannaensis Schwendinger, 2005 in China and Thailand, C. siamensis Schwendinger, 2005 in Thailand and Laos) (World Spider Catalog 2016). In this study, three Cyclocosmia species collected from China and Vietnam are diagnosed and described, one of which is believed to be new to science. One of the species is a new record from China (Yunnan) and Vietnam, based on the morphology of female specimens. Ideally, both male and female specimens would be included in the description of new species; however, it is extremely difficult to obtain adult males of trapdoor spiders. Indeed, we were unable to obtain male Cyclocosmia specimens in this study. By searching and digging burrows, we obtained a few immature and/or adult female specimens. Males are short-lived and 
leave the burrow immediately after they reach maturity to search for females (Haupt and Shimojana 2001; Haupt 2003). Therefore, collecting males is only possible at certain times of the year, and therefore is not feasible during each field trip.

\section{Materials and methods}

Specimens were studied using an Olympus SZX16 stereomicroscope. Anatomical details were examined and photographed with on Olympus BX51 compound microscope and a Canon 7D camera. Genitalia were cleared in boiling $\mathrm{KOH}$ for a few minutes to dissolve soft tissues. All the specimens were deposited at the Centre for Behavioural Ecology and Evolution (CBEE), College of Life Sciences, Hubei University, Wuhan, China. All lengths are given in millimetres. Leg and palp measurements are given in the following order: total length (femur + patella + tibia + metatarsus + tarsus).

Abbreviations used:
ALE anterior lateral eye;
AME anterior median eye;
PLE posterior lateral eye;
PME posterior median eye;
MOA median ocular area;
PMS posterior median spinneret;
PLS posterior lateral spinneret.

\section{Taxonomy}

\section{Genus Cyclocosmia Ausserer, 1871}

Cyclocosmia Ausserer, 1871, type species Cyclocosmia truncata (Hentz, 1841): 144.

Chorizops Ausserer, 1871, type species by original designation Actinopus loricatus C. L. Koch, 1842, synonymised by Gertsch \& Platnick, 1975: 15 .

Diagnosis. The genus Cyclocosmia differs from all the other genera of Ctenizidae by the abruptly truncated abdomen forming a heavily sclerotized disc that is enhanced by a series of raised ribs and grooves (Gertsch and Platnick 1975) (Fig. 1B-D, I-L). Genera Galeosoma and Idiosoma of the family Idiopidae have the similar abdominal form as Cyclocosmia, but the genus Galeosoma can be distinguished from Cyclocosmia by the distinctly truncated abdomen without ribs or grooves, and the genus Idiosoma can be distinguished from Cyclocosmia by the moderately truncated abdomen, even though with ribs or grooves. Moreover, the arrangement of eyes is also different, Cyclocosmia with two eye rows, yet the two genera of Idiopidae with three eye rows (Gertsch and Platnick 1975; Zhu et al. 2006). 


\section{Cyclocosmia ricketti (Pocock, 1901)}

Fig. 1

Halonoproctus ricketti Pocock, 1901: 209, pl. 21, f. 1 (described female of Pocock, 1901 was not examined).

Cyclocosmia ricketti Simon, 1903: 887, f. 1044-1047; Gertsch \& Platnick, 1975: 18, f. 28-29, 32, 36; Song, Zhu \& Chen, 1999: 36, f. 16H, K-L; Schwendinger, 2005: 227, f. 2-8, pl. 1D; Zhu, Zhang \& Zhang, 2006: 120, f. 1, 2A-E; Zhang, Gao \& Li, 2007: 385, f. 101; Yin et al., 2012: 134, f. 13a-e.

Material examined. Female (XUC-2013-013), Mt. Nan, Ciping Town, Jinggang-

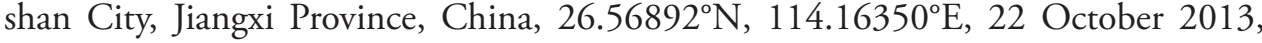
collected by F.X. Liu, X. Xu and C. Xu; 1 Juvenile (C-2016-001), Cemetery of Jinggangshan Revolutionary Martyrs, Ciping Town, Jinggangshan City, Jiangxi Province, $26.57873^{\circ} \mathrm{N}, 114.15960^{\circ} \mathrm{E}, 31$ August 2016 , collected by X. Xu; 1 female (Tianzishan-2016), Mt. Tianzi, Zhangjiajie, Hunan Province, China, $29.40^{\circ} \mathrm{N}, 110.44^{\circ} \mathrm{E}, 10$ March 2016, collected by S.F. Peng.

Diagnosis. Cyclocosmia ricketti differs from other species of Cyclocosmia by the character of 23-33 radiating ribs on each side of abdominal disc (Fig. 1I-L), and parallel-sided spermathecae (Fig. 1G, H). It can be distinguished from C. latusicosta by the lack of the elevated central zone inside the upper pair of muscle impressions (Fig. 1I-L). More details see Zhu et al. 2006.

Description. Female (XUC-2013-013). Total length, including chelicerae, 14.00; carapace 6.50 long, 5.40 wide; abdomen 6.50 long, 9.30 wide. Carapace red-brown and smooth, with a few marginal hairs in the front of ocular area, four long bent bristles in longitudinal row running through ocular area, the posterior two bristles have been damaged (Fig. 1D). Ocular area with a black ring around each eye of the anterior eye row and a black band in front of fovea. Cervical groove and radial furrows distinct. Fovea deep and procurved, U-shaped, its greatest width occupying one fourth of carapace width at that point. Eyes set on low tubercle, ocular 0.70 long, 1.70 wide anteriorly, 1.70 wide posteriorly. Clypeus height 0.60 . Anterior eye row straight and posterior eye row recurved, both rows almost equal in length. Ratio of eyes, ALE: AME: PLE: PME (0.40: 0.25: 0.30: 0.20). ALE-AME 0.25, AME-AME 0.20, PLEPME 0.10, PME-PME 0.70. MOA 0.70 long, 0.70 wide in front, 1.10 wide at back. Chelicerae red-brown, inner margin with eight teeth and six denticles, outer margin with seven teeth and four denticles. Rastellum raised on prominent angled projection and consisting of many short black teeth. Labium yellow-brown, 1.10 long, 1.20 wide, with three black cuspules anteriorly. Maxilla yellow-brown, 2.30 long, 1.50 wide, with a few black cuspules at base.

Legs yellow-brown. Tibiae and tarsi of pedipalps, and distal three segments of legs I and II with numerous horn-like spines, metatarsus III with a few short dorsal and two ventrally spines, tarsus III with a few dark spines prolaterally and ventrally. Legs each with three tarsal claws, paired claws with a single large tooth, unpaired claw lacking 


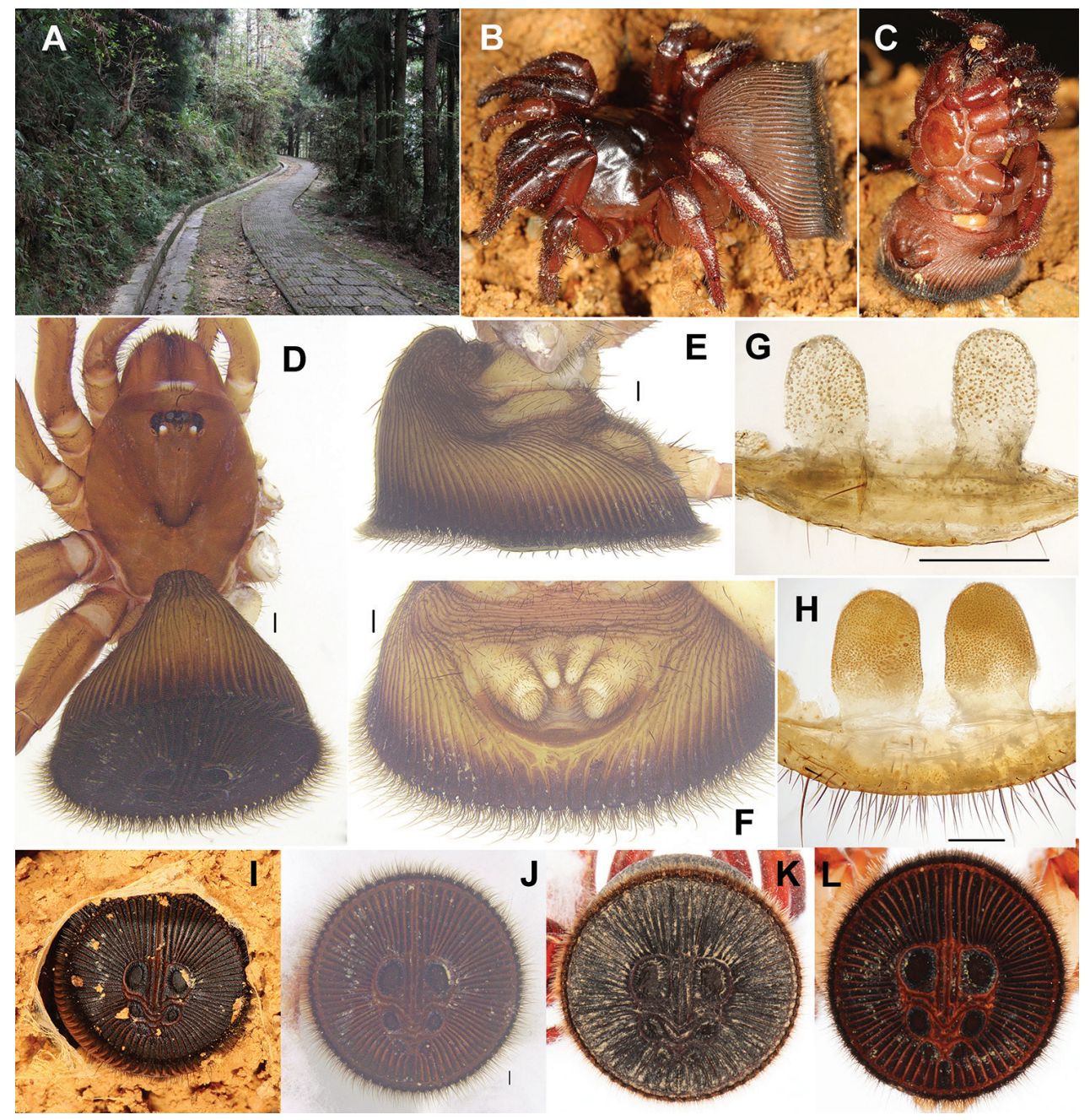

Figure I. Cyclocosmia ricketti (Pocock, 1901) A habitat B-D habitus of female (XUC-2013-013) $\mathbf{E}$ abdomen, lateral view $\mathbf{F}$ posterior portion of opisthosoma, ventral view, showing spinnerets $\mathbf{G}$ female genitalia (XUC-2013-013), dorsal view $\mathbf{H}$ female genitalia (tianzishan-2016), dorsal view I showing opisthosomal disc in plugging position (XUC-2013-013) J-L abdomen, caudal view (J XUC-2013-013 K Tianzishan-2016 L C-2016-001). Scale bars $0.5 \mathrm{~mm}$.

tooth. Palp with a single claw bearing one tooth. Measurements: palp $10.06(4.00+$ $2.10+2.30+2.20)$, leg I $11.00(4.20+1.60+2.50+1.50+1.20)$, leg II $8.60(3.20+$ $1.40+1.50+1.40+1.10)$, leg III $8.50(3.50+1.30+1.20+1.00+1.50)$, leg IV $12.20(4.00+2.60+2.10+2.00+1.50)$. Formula: 4123 .

Abdomen funnel-shaped and dark yellow-brown (Fig. 1D). Caudal disc slightly concave, 8.80 in transversal diameter and 8.50 in longitudinal diameter, with two rids running dorso-ventrally and 32/33 (XUC-2013-013), 29/28 (Tianzishan-2016), 33/33 (C-2016-001) radiating ribs on each side. Abdominal disc with six well-marked 
muscle impressions (Fig. 1I-L). Four spinnerets, with inner pair small and one-segmented, and outer pair slightly longer and three-segmented (Fig. 1F). Genitalia with paired spermathecae (Fig. 1G, H), sack-like, parallel-sided, the length of each one is more or less one and a half times its width: length $=0.55 \mathrm{~mm}$, width $=0.33 \mathrm{~mm}$ (XUC-2013-013); length $=1.17 \mathrm{~mm}$, width $=0.78 \mathrm{~mm}$ (Tianzishan-2016).

Distribution. China (Fujian, Hunan, Jiangxi, Zhejiang, Sichuan).

Remarks. Cyclocosmia ricketti was diagnosed and described based on the holotype female collected from Fujian, and since then, according to the character of the abdominal disc with 23-33 ribs on each side, researchers have identified specimens collected from Hunan, Zhejiang, Sichuan as C. ricketti. Here, a specimen collected from Jiangxi is also identified as $C$. ricketti on the basis of this character; $C$. ricketti was not recorded in Jiangxi before. Males remain unknown.

\section{Cyclocosmia latusicosta Zhu, Zhang \& Zhang, 2006}

Fig. 2

Cyclocosmia latusicosta Zhu, Zhang \& Zhang, 2006: 121, f. 4, 5A-D, 6A-J (described female of Zhu, Zhang \& Zhang, 2006 was not examined); Zhang, Gao \& Li, 2007: 385, f. 1-100.

Material examined. Female (17-1-2013), Tam Dao Town, Tam Dao National Park, Vinh Phuc Province, Vietnam, $21.45847^{\circ} \mathrm{N}, 105.64834^{\circ} \mathrm{E}, 17$ January 2013 , collected by D. Li, F.X. Liu and X. Xu; Female (XUC-2016-017), Cuc Phuong National Park, Nho Quan, Ninh Binh Province, Vietnam, 20.34915 N, 105.59927E, 31 May 2016, D. Li, F. Li and F.X. Liu; 3 females and 1 juveniles (LH-2016-(002-005)), rubber plantation, Hekou City, Yunnan, $22.537^{\circ} \mathrm{N}, 103.942^{\circ} \mathrm{E}, 15$ September 2016, F. Li, F.X. Liu and L. Yu.

Diagnosis. Females of C. latusicosta are different from other Cyclocosmia species by their abdominal disc with 22-27 wide ribs on each side, each upper muscle impression with an elevated zone connected to the outer rim of each upper muscle impression, and the length of spermathecae being more or less 1.7-2.0 times longer than width.

Description. Female. Total length, including chelicerae, 17.10-30.20; chelicerae 2.60-4.90 long; carapace 7.50-14.50 long, 6.71-12.50 wide; abdomen 9.30-11.60 long, 12.20-18.50 wide. Carapace red-brown and smooth, with a few marginal hairs and a long bristle in front of ocular area, six long bent bristles in longitudinal row and two bristles in latitudinal running through ocular area (Fig. 2A). Ocular area black, with a black band in front of fovea and beside ocular area respectively. Cervical groove and radial furrows distinct. Fovea deep and procurved, U-shaped, its greatest width occupying one fifth of carapace width at that point. Eyes set on low tubercle, ocular 0.90 long, 2.00 wide anteriorly, 2.00 wide posteriorly, occupying one fourth of carapace width at that point. Clypeus height 2.40. Both anterior and posterior eye rows straight and almost equal in length. Ratio of eyes, ALE: AME: PLE: PME (0.38: 0.25: 0.20: 

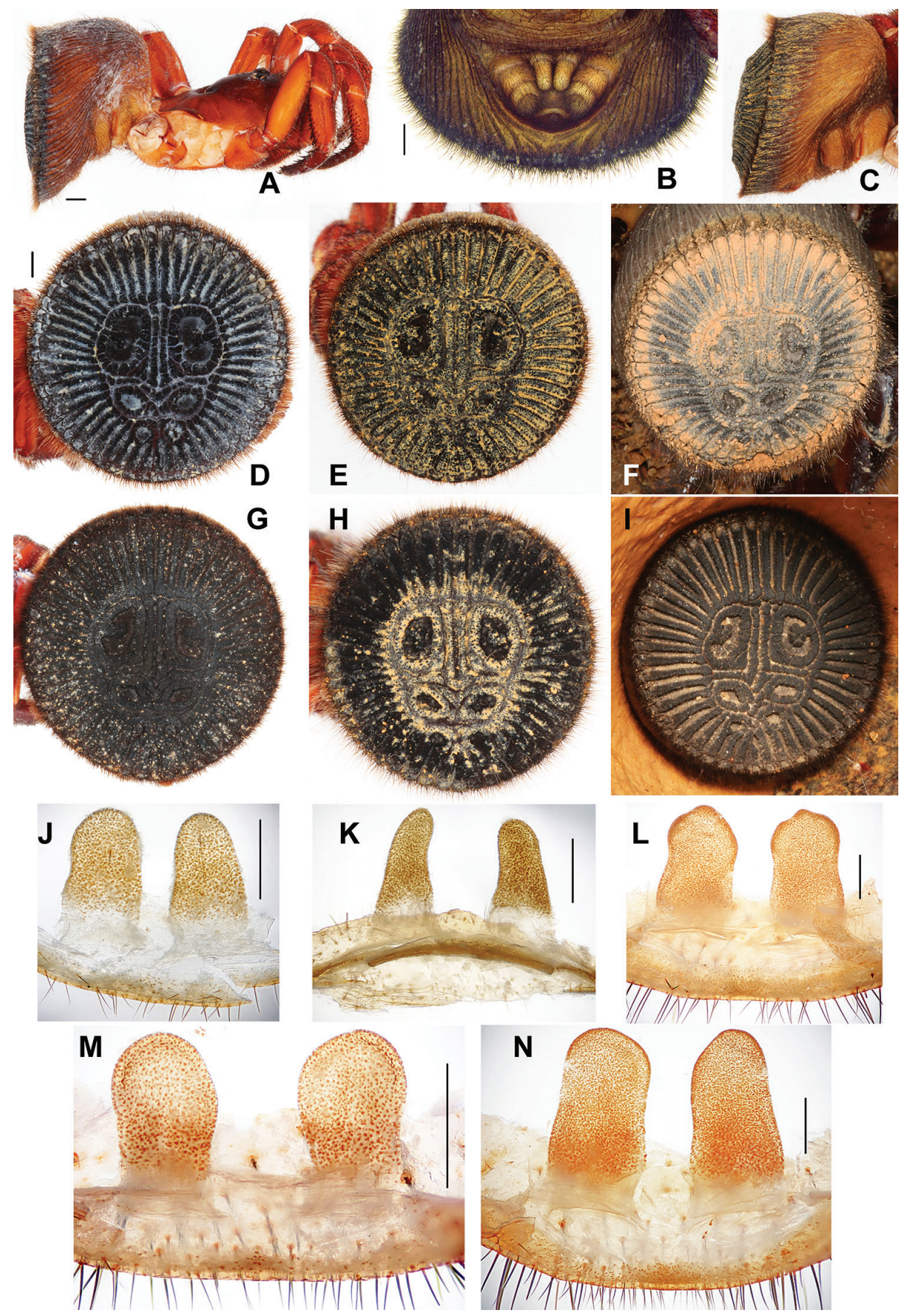

Figure 2. Cyclocosmia latusicosta Zhu, Zhang \& Zhang, 2006 A habitus of female, lateral view (17-I-2013) B posterior portion of opisthosoma, ventral view, showing spinnerets $\mathbf{C}$ abdomen, lateral view (XUC2016-017) D-I abdomen, caudal view (D 17-I-2013 E XUC-2016-017 F LH-2016-002 G LH-2016-003 H LH-2016-004 I LH-2016-005) J-N female genitalia (J 17-I-2013 K XUC-2016-017 L LH-2016-003 M LH-2016-004 N LH-2016-005), dorsal view. Scale bars A, B, D 1mm, J-N 0.5 mm. 
0.20). ALE-AME 0.28, AME-AME 0.28, PLE-PME 0.02, PME-PME 0.80. MOA 0.80 long, 0.78 wide in front, 1.20 wide at back. Chelicerae red-brown, inner margin with six teeth and one denticle, outer margin with seven teeth and four denticles. Rastellum raised on prominent angled projection and consisting of many short black teeth. Labium yellow-brown, 1.40 long, 1.40 wide, with three black cuspules anteriorly. Maxilla yellow-brown, 15.90 long, 1.20 wide, with a few black cuspules at base.

Legs yellow-brown. Tibiae and tarsi of pedipalps, and distal three segments of legs I and II with numerous horn-like spines, metatarsus III with a few short dorsal and ventrally spines, tarsus III with a few dark spines prolaterally and ventrally. Legs each with 3 tarsal claws, paired claws with a single large tooth, unpaired claw lacking tooth. Palp with a single claw bearing one tooth. Measurements: palp $12.10(4.20+1.80+$ $3.10+3.00)$, leg I $14.00(5.00+2.00+3.00+2.00+2.00)$, leg II $11.20(4.10+2.00+$ $2.00+1.50+1.60)$, leg III $11.00(4.10+1.00+2.20+1.70+2.00)$, leg IV 15.20 $(5.00+3.00+2.50+2.50+2.20)$. Formula: 4123 .

Abdomen funnel-shaped and dark yellow-brown (Fig. 2A). Caudal disc slightly convex, 11.00 in transversal diameter and 10.20 in longitudinal diameter, with two rids running dorso-ventrally (with small interrupt at the groove outer the upper pair muscle impressions) and 24/25 (17-1-2013), 23/25 (XUC-2016-017), 24/23 (LH-2016-002), 28/26 (LH-2016-003), 23/24 (LH-2016-004), 22/23 (LH-2016-005) radiating ribs on each side (Fig. 2D-I). Abdominal disc with six well-marked muscle impressions. All rims within the muscle impression zone with distinct granular structures in different sizes (Fig. 2D-I). Four spinnerets, with inner pair small and one-segmented, and outer pair longer and three-segmented. Paired spermathecae sack-like, parallel-sided, each one with a length 1.7-2.0 times its width (Fig. $2 \mathrm{~J}-\mathrm{N})$, length $=0.86 \mathrm{~mm}$, width $=$ $0.43 \mathrm{~mm}$ (17-1-2013), length $=0.94 \mathrm{~mm}$, width $=0.39 \mathrm{~mm}$ (XUC-2016-017), length $=1.42 \mathrm{~mm}$, width $=0.83 \mathrm{~mm}$ (LH-2016-003), length $=0.73 \mathrm{~mm}$, width $=0.40 \mathrm{~mm}$ (LH-2016-004), length $=1.67 \mathrm{~mm}$, width $=0.83 \mathrm{~mm}$ (LH-2016-005).

Distribution. China (Guangxi, Yunnan), Vietnam (Vinh Phuc, Ninh Binh).

Remark. Cyclocosmia latusicosta was diagnosed based on the holotype female collected from Guangxi Province, China, near the border to Vietnam. This study provides a new record from China (Yunnan) and Vietnam. We preliminarily treated the differences in the spermathecae among five specimens (17-1-2013, XUC-2016-017, $\mathrm{LH}-2016-003 / 004 / 005)$ as the intraspecific variation according to the work of Zhang et al. (2007). Males remain unknown.

\section{Cyclocosmia liui Xu, Xu \& Li, sp. n.}

http://zoobank.org/BAD72BC4-CC48-44DF-BA1A-138BAAB915B5

Fig. 3

Holotype. Female (C-XUX-2015), Mt. Fanjing, Taiping Town, Jiangkou County, Tongren City, Guizhou Province, China, $27.8513^{\circ} \mathrm{N}, 108.7779^{\circ} \mathrm{E}, 25$ May 2015, collected by Z.Q. Li, F.X. Liu and M. Yan. 

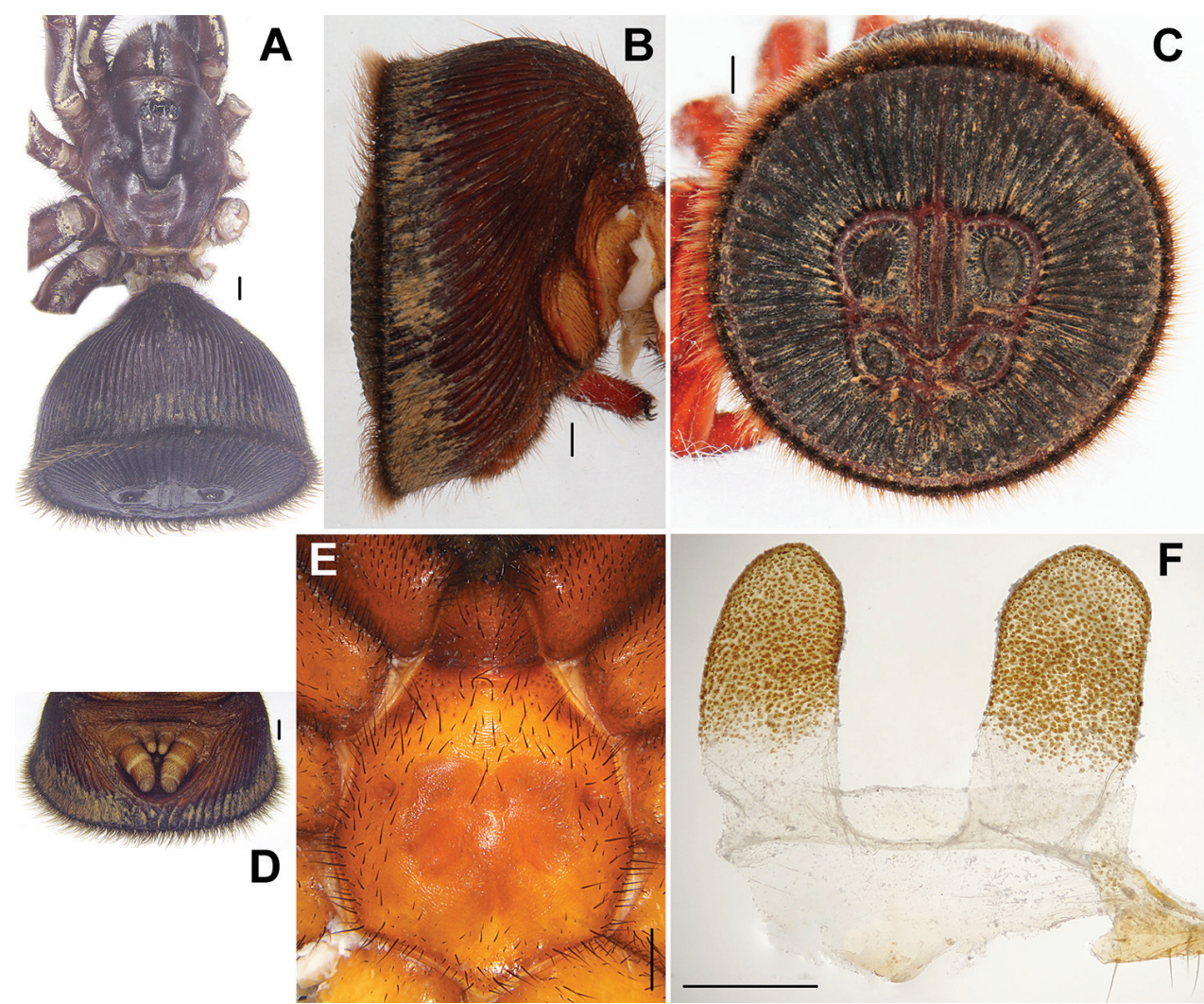

Figure 3. Cyclocosmia liui Xu, Xu \& Li sp. n. A habitus of female (C-XUC-2015) B abdomen, lateral view $\mathbf{C}$ abdomen, caudal view $\mathbf{D}$ posterior portion of opisthosoma, ventral view, showing spinnerets $\mathbf{E}$ sternum, ventral view $\mathbf{F}$ female genitalia, ventral view. Scale bars $\mathbf{A}-\mathbf{E} 1 \mathrm{~mm}, \mathbf{F} 0.5 \mathrm{~mm}$.

Etymology. The specific name is taken from the family name of the collector Fengxiang Liu, who joined all collecting trips and has worked on spiders for a few decades.

Diagnosis. Female of $C$. liui sp. n. can be distinguished from $C$. ricketti by abdominal disc with 33/34 ribs on each side, the rims of the upper pair muscle impressions with distinct granular structures in almost same size, the groove around the six well-marked muscle impressions dark red colour, and the middle pair muscle impressions with an elevated central zone connected to the inner rim of muscle impression (Fig. 3C). It is similar to C. latusicosta in the shape of spermathecae, but can be distinguished from the latter by abdominal disc with 33/34 ribs on each side (Fig. 3C).

Description. Total length, including chelicerae, 22.50; chelicerae 3.40 long; carapace 9.70 long, 8.00 wide; abdomen 11.50 long, 14.20 wide. Carapace dark brown and smooth, with a few marginal hairs and a long bristle in the front of ocular area, three long bent bristles in longitudinal row running through ocular area (Fig. 3A). Carapace widest at coxae II. Ocular area black. Cervical groove and radial furrows distinct. 
Fovea deep and procurved, U-shaped, its greatest width occupying one fourth of carapace width at that point. Eyes set on low tubercle, ocular 1.00 long, 2.24 wide anteriorly, 2.20 wide posteriorly, occupying one fourth of carapace width at that point (Fig. $3 \mathrm{~A})$. Clypeus height 2.10. Both anterior and posterior eye rows straight and almost equal in length. Ratio of eyes, ALE: AME: PLE: PME (0.53: 0.34: 0.43: 0.33). ALEAME 0.35, AME-AME 0.25, PLE-PME 0.05, PME-PME 1.00. MOA 1.00 long, 0.93 wide in front, 1.66 wide at back. Chelicerae red-brown, inner margin with eight teeth and six denticles between, outer margin with seven teeth and three denticles between. Rastellum raised on prominent angled projection and consisting of many short black teeth. Labium brown, 1.90 long, 1.70 wide, with three black cuspules anteriorly. Maxilla dark-brown, 18.5 long, 1.5 wide, with a few black cuspules at base. Sternum 5.50 long, 5.00 wide, with large, irregularly shaped sigilla in the centre (Fig. 3E).

Legs brown. Tibiae and tarsi of pedipalps, and distal three segments of legs I and II with numerous horn-like spines, metatarsus III with a few short dorsal ventrally spines, tarsus III with a few dark spines prolaterally and ventrally. Legs each with three tarsal claws, paired claws with a single large tooth, unpaired claw lacking tooth. Palp with a single claw bearing one tooth. Measurements: palp $14.50(5.60+2.30+3.00+3.60)$, leg I $17.50(6.00+3.00+3.70+2.80+2.00)$, leg II $14.40(5.10+2.30+3.00+$ $2.20+1.80)$, leg III $14.80(5.20+3.00+2.30+2.20+2.10)$, leg IV $17.70(5.50+$ $3.20+3.50+3.10+2.40)$. Formula: 4132 .

Abdomen funnel-shaped and dark brown. Caudal disc slightly convex (Fig 3A, B), 13.20 in transversal diameter and 12.30 in longitudinal diameter, with two rids running dorso-ventrally (with small interrupt at the groove outer the upper pair muscle impressions) and 34/35 radiating ribs on each side (Fig 3C). Abdominal disc with six well-marked muscle impressions, the middle pair muscle impression with an elevated central zone connected to the inner rim of muscle impression. Four spinnerets, with inner pair small and one-segmented, and outer pair much longer and three-segmented (Fig. 3D). Paired spermathecae sack-like, parallel-sided, the length of each one is more or less two times its width (Fig. 3F), length $=1.09 \mathrm{~mm}$, width $=0.56 \mathrm{~mm}$.

Male. Unknown.

Distribution. China (Guizhou).

\section{Acknowledgements}

This study was supported by the grants from the National Natural Sciences Foundation of China (NSFC-31601850 and NSFC-31272324) and the Singapore Ministry of Education (MOE) AcRF Tier 1 grant (R-154-000-638-112). We value the positive feedback from Hirotsugu Ono and Vera Opatova and thank them for their insightful and constructive comments on the manuscript. We are grateful to Ziqi $\mathrm{Li}, \mathrm{Mu} \mathrm{Yan}$, Zengtao Zhang, and Shuaifu Peng for their field work. We also thank the staff of the Centre for Behavioural Ecology and Evolution (CBEE, Hubei University) for all their help and support throughout this study. 


\section{References}

Bond JE, Coyle FA (1995) Observations on the natural history of an Ummidia trapdoor spider from Costa Rica (Araneae, Ctenizidae). Journal of Arachnology 23: 157-164.

Buchli HHR (1969) Hunting behavior in the Ctenizidae. Integrative and Comparative Biology 9(1): 175-193. https://doi.org/10.1093/icb/9.1.175

Decae AE (2010) The genus Ummidia Thorell 1875 in the western Mediterranean, a review (Araneae: Mygalomorphae: Ctenizidae). Journal of Arachnology 38: 328-340. https://doi. org/10.1636/A09-85.1

Garrison NL, Rodriguez J, Agnarsson I, Coddington JA, Griswold CE, Hamilton CA, Hedin M, Kocot KM, Ledford JM, Bond JE (2016) Spider phylogenomics: untangling the Spider Tree of Life. PeerJ 4: e1719. https://doi.org/10.7717/peerj.1719

Gertsch WJ, Platnick NI (1975) A revision of the trapdoor spider genus Cyclocosmia (Araneae, Ctenizidae). American Museum Novitates 2580: 1-20.

Gertsch WJ, Wallace HK (1936) Notes on new and rare American mygalomorph spiders. American Museum Novitates 884: 1-25.

Haupt J (2003) The Mesothelaea monograph of an exceptional group of spiders (Araneae: Mesothelae) (Morphology, behaviour, ecology, taxonomy, distribution and phylogeny). Zoologica 154: 1-102.

Haupt J, Shimojana M (2001) The spider fauna of soil banks: the genus Latouchia (Arachnida, Araneae, Ctenizidae) in southern Japan and Taiwan. Zoosystematics and Evolution 77(1): 95-110. https://doi.org/10.1002/mmnz.20010770116

Hunt RH (1976) Notes on the ecology of Cyclocosmia truncata (Araneae, Ctenizidae) in Georgia. Journal of Arachnology 3: 83-86.

Opatova V, Bond JE, Arnedo MA (2013) Ancient origins of the Mediterranean trap-door spiders of the family Ctenizidae (Araneae, Mygalomorphae). Molecular Phylogenetics and Evolution 69(3): 1135-1145. https://doi.org/10.1016/j.ympev.2013.08.002

Opatova V, Bond JE, Arnedo MA (2016) Uncovering the role of the Western Mediterranean tectonics in shaping the diversity and distribution of the trap-door spider genus Ummidia (Araneae, Ctenizidae). Journal of Biogeography. https://doi.org/10.1111/jbi.12838

Ortiz D (2007) Ummidiinae, a new replacement name for pachylomerinae Simon 1889 (Araneae: Ctenizidae). Boletín Sociedad Entomológica Aragonesa 40: 395-396.

Raven RJ (1985) The spider infraorder Mygalomorphae (Araneae): cladistics and systematics. Bulletin of American Museum of Natural History 182: 1-180.

World Spider Catalog (2016) World spider catalog. Natural History Museum Bern. http:// wsc.nmbe.ch [version 17.5, accessed on 19 December 2016]

Zhang XF, Gao JC, Li SQ (2007) Morphological variation in female Cyclocosmia latusicosta (Araneae, Ctenizidae). Acta Zootaxonomica Sinica 32: 385-390.

Zhu MS, Zhang JX, Zhang F (2006) Rare spiders of the genus Cyclocosmia (Arachnida: Araneae: Ctenizidae) from tropical and subtropical China. The Raffles Bulletin of Zoology 54: $119-124$. 